\title{
Electronic Collection Growth: An Academic Library Case Study
}

\section{Introduction}

Not a week passes in an academic library without major electronic resource additions or revisions - new titles, changed titles, cancelled titles, platform upgrades and feature additions, or migrations to new platforms and vendors. Growth is not restricted simply to more online versions of print equivalents - more bibliographic databases, e-journals and e-books. "Born digital" genres are on the rise - numeric data resources, image galleries, multimedia reference works, and interactive tools. Over a remarkably short period of time, the range and complexity of commercial and open access electronic resources has expanded - from bibliographic indexes to full text, from electronic journals to electronic books, from text-based interfaces to GUI (Graphical User Interface), from plain text to digitized facsimile to "born digital" and multimedia.

Many academic library staff express feelings of being overwhelmed or frustrated by the rapid growth and volatility associated with electronic collections and their impact on public and technical services. The patron experience is similarly challenging, and it is little wonder that many patrons retreat to the safety and simplicity of the Google

juggernaut. While the academic sector may readily talk about electronic collection growth, there is little published numeric data measuring that growth, either by number of titles or other defining category such as resource type or subject area. While North American academic libraries gather electronic collection statistics annually for ARL (Association of Research Libraries) and in Canada, additionally for CARL (Canadian 
Association of Research Libraries), the statistics are inconsistent. The type of data gathered changes with great frequency, and the interpretation of data fields varies extensively across libraries and even within libraries from year to year as staff change, so that it is not recommended to conduct longitudinal studies of electronic resource trends using these data. At the same time, few academic libraries maintain consistent tracking data to describe local growth. Individual staff may keep on-going records in local spreadsheets and reports; but meaningful growth statistics and analyses of that growth are not systematically reported in library systems. Hard statistical evidence is needed to speak convincingly to library and university administrators and boards about electronic collection growth and complexity, and win support for additional funds and staff, and infrastructure changes. Statistical evidence is more convincing and likely to prompt change than earnest narratives short on specifics.

This paper describes and analyses electronic resources growth at the University of Saskatchewan Library, a large Canadian academic library, over a twelve-year time series - 1996-1997 to 2007-2008. It briefly relates that growth to the historical evolution of library databases and analyzes growth in terms of development stages and internal and external impacts. While the experience of a single academic library cannot be generalized to other libraries, it is proposed that libraries across North America of a similar size and similar electronic resource adoption time lines share similar growth experiences, especially when they also have similar histories related to growth, vendors and consortia.

A thorough literature search did not find similarly conducted research. Quantitative research on electronic collection growth, where it exists, is primarily focused on electronic journals, or uses other evidence such as spending data or usage. 
This paper takes a unique approach based on numeric counts of electronic resources that do not have standardized titles or numbers, may have ambiguous or volatile descriptions, and launch frequent structural changes.

\section{Background}

The systematic indexing of documents in North America began in the latter half of the $19^{\text {th }}$ century partly in response to the development of professional standards and practice in the new discipline of information science. The American Library Association (ALA) identified the need for periodical indexing at its founding meeting in 1876. Index Medicus, "a monthly classified record of the current medical literature of the world," launched in 1879 (Lerner, 1999). Poole's Index to Periodical Literature, an index to 479 American and English periodicals back to 1802, appeared in 1882 (Wedgeworth, 1993). Print bibliographic indexes covering periodical literature, books, and grey literature, became standard finding tools in $20^{\text {th }}$ century libraries until electronic equivalents began to supplant them at the end of the century.

In his seminal 1945 article “As We May Think," (Bush, 1945) in the Atlantic Monthly, Vannevar Bush proposed a future device, the "memex," conceived as early as the 1930s, as a technical solution to the problem of managing and accessing the burgeoning scientific literature proliferating in his own time, resulting he thought from that era's growing confidence in scientific activity and increased specialization. Memex was envisioned as a desktop electromechanical device for storing and retrieving an individual's information (books, records, and communications) on microfilm, combined 
with a mechanical retrieval system (Lemelson-MIT Program, 2002). It was a vision of a personal automated library of the future.

The first decks of punched cards read by computer programs in the early 50s, like those that created the U.S. Bureau of the Census numeric databases in 1951, were precursors of online databases (Neufeld and Cornog, 1986). The first operational computer-based bibliographic search system, was created in 1954 by the Naval Ordnance Test Station (NOTS) in California in response to an automated indexing project initiated by library staff. By the late 1950s, large-scale online information retrieval system experiments were underway (Bourne and Bellardo Hahn, 2003).

In the mid-1960s, computerized photocomposition technology (or computerdriven typesetting) combined with advances in computer hardware and software, led to greater efficiencies for print bibliographic index publishing. Publishers were quick to realize that the resulting bibliographic data stored on magnetic tapes could be leased or sold to users interested in searching bibliographic data more efficiently (Aquirre, 1976). They sold their word-oriented database by-products, with more or less effective search interfaces, as databases on magnetic tape.

Until 1970, batch searching was the primary retrieval technology. Batched coded searches were run consecutively against a database loaded on a computer (Neufeld and Cornog, 1986). On-demand batch retrospective search and retrieval of references in the National Library of Medicine's (NLM) information system, MEDLARS (Medical Literature Analysis and Retrieval System), with results delivered off-line and often taking several weeks, was launched in 1963 and first offered to the public in 1964 (Wedgeworth, 
1993). Chemical Abstracts was offered to the public on magnetic tape in 1965, and INSPEC in 1970.

While batch processing made efficient use of a computer's time, it was expensive, inefficient from the user's standpoint, and not very user friendly. Consequently investigations into online interactive searching occurred early on. System Development Corporation (SDC) demonstrated the first online interactive search system in 1961 (Wedgeworth, 1993). However, regular non-experimental online (interactive) service to networked in-house or institutional users did not occur until 1968, and commercial online service was not available until 1971 (Bourne, 1999). Commercial communications networks such as Tymnet (primarily in the United States) and DATAPAC (primarily in Canada), were developed in the late 1960's and made available to the public in 1972, enabling remote online access to database services (Hawthorne, 2008).

By 1974, DIALOG Information Services offered 18 online databases to the public in a dial-up service. By the late 1980s, SDC offered more than 60 databases, primarily covering science and technology. By 1985, DIALOG had more than 200 databases covering a much broader range of disciplines. In Canada, the Canada Institute for Scientific and Technical Information (CISTI) released CAN/OLE (Canadian Online Enquiry) in 1972, “an online information retrieval system providing access to Canadian and international databases in the fields of science and technology" (Krym and VanBuskirk, 2001).

Neufeld and Cornog report on studies that show that 12-20 databases existed in 1965 and about 25 in 1968. By 1970, about 50-100 numeric and word databases were available for public use, although only about half of these were available online (Neufeld 
and Cornog, 1986). By the end of 1976, hundreds of databases were available on magnetic tape and downloadable to local servers in libraries (Bourne, 1999). By the late 1970 's, the number had swelled to more than 360, including at least 40 abstracting and indexing services. In the 1980's as more databases were designed primarily for the enduser rather than skilled library intermediaries the numbers of databases grew. In 1984, over 2,800 databases were available (Neufeld and Cornog, 1986) (Williams, 1985). According to Neufeld and Cornog, this ten-fold increase stemmed in part from the increased participation of commercial publishers and vendors in a market previously dominated by government and non-profit agents (Neufeld and Cornog, 1986). The profitmaking incentive continues to drive the proliferation of databases to this day.

Bibliographic databases on CD-ROMs became available in the mid-80s. The CDROMs included search interfaces designed for the end-user (Hawthorne, 2008). Libraries made them available from public workstations on-site instead of over expensive communication networks via mediated searches. Dedicated CD-ROM “jukeboxes", made several databases conveniently available from a dedicated workstation or from workstations connected to local area networks (LANs). By the 1990s selected databases were acquired on the more efficient magnetic tapes and loaded on local servers for availability over LANs (Wedgeworth, (1993). Users flocked to these non-mediated online resources. The end of the monopoly role of the librarian database searcher soon followed.

Access to databases via dedicated international communication networks such as Tymnet was largely displaced by the development of the Internet in the 1990s. Like CDROMs or networked databases on magnetic tape, databases delivered over the Internet were end-user friendly and efficient and did not cost the user anything. The Internet also 
had compelling new advantages, including 24 hour availability, improved currency with more frequent updates, and remote access. There were also significant management advantages, including avoiding the high cost of LAN maintenance. The initial volatility of Internet access initially stalled wholesale migration to Internet access over locally hosted servers. However, the greater robustness of Internet delivery by the new Millennium boosted the migration into a flood. Internet access became the access of choice for new resources and libraries migrated existing databases on CD-ROM's to the Internet where price and funding permitted.

\section{Electronic Resources at the University of Saskatchewan Library}

Like most academic libraries in North America, the University of Saskatchewan Library rapidly adopted new bibliographic and full text databases and made them available to their patrons. Mediated batch mode Selective Dissemination Information (SDI) services and off-line searching of bibliographic databases over commercial networks were offered to patrons as early as the late 1960's shortly after such services became available. Mediated online bibliographic database searching followed shortly after availability in 1972. By the early 1980's, mediated searching was offered from several service points, including branch libraries. By 1987, there were as many as eight service points and the library had accounts with a range of information retrieval services, including: DIALOG, BRS (Bibliographic Retrieval Service), SDC, CAN/OLE, MEDLINE, and the Scientific and Technical Information Network (STN)/ Chemical Abstracts Service (CAS) Online. With the exception of a few very specialized services, mediated searching all but ended at the library in 1994. By then, the majority of online services and SDI had been abandoned for unmediated patron access to resources on CD- 
ROM, LAN, or the Internet. There were 51 databases listed in the library's databases A-Z list in 1996-1997. By 2001, the primary delivery mode for databases was the Internet. By 2007-2008, there were 646 electronic resources listed in the A-Z list.

\section{Methodology}

This study examined public and in-house sources at the University of Saskatchewan Library to identify available electronic resources over a twelve-year time series, the fiscal years from 1996-1997 to 2007-2008. Electronic resources were limited to those listed in the databases A-Z list posted on the library's website. The list excludes most individual electronic books and journals. Collected data was collated and analyzed to demonstrate electronic resource growth patterns.

\section{The University of Saskatchewan Library}

The University of Saskatchewan is a large Western Canadian university, awarding doctoral degrees in the humanities, social sciences, and sciences. It offers professional degrees in medicine, dentistry and veterinary medicine, as well as other health professions, in addition to the fields of business, education, engineering, and law. The University falls into the Carnegie CompDoc/MedVet (comprehensive doctoral with medical/veterinary) library classification (The Carnegie Foundation for the Advancement of Teaching, 2009). The library is a member of several library consortia, including the Saskatchewan Multitype Database Licensing Program (MDLP), the Saskatchewan Health Information Resources Partnership (SHIRP), the Council of Prairie and Pacific University Libraries (COPPUL) and the Canadian Research Knowledge Network (CRKN), and it is a member of the Center for Research Libraries (CRL) and OCLC. 
According to the Association of Research Libraries (ARL) 2006-2007 statistics, the library's total expenditure on all electronic resources (including databases, and electronic books and journals) was CA $\$ 6,369,649$, or about 50 per cent of its library materials expenditure (Kyrillidou and Bland, 2008). By 2008-09, the total electronic resource expenditure exceeded 50 per cent.

\section{2-Year Time Series}

The study covers twelve fiscal years, from 1996-1997 to 2007-2008. The fiscal year (May 1 to April 30) was selected as the measurement year rather than the calendar year, since it is the standard period for ARL and CARL statistics. A fiscal year reflects the actual resource growth potential or acquisition power of the library's annual budget.

\section{The "Databases" A-Z List-A Virtual Reference Shelf}

The library maintained a "databases" A-Z list accessible on its public web site (See: https://library.usask.ca/resource for the current list), throughout the time series. Early on, the library recognized the need to highlight its core electronic resources by maintaining a separate A-Z list as a primary finding tool. The resources are also included in the library catalog. Arguably, the A-Z list is equivalent to a virtual reference shelf. Many resources are online equivalents of print titles previously shelved in a non-circulating reference collection. Over time, a growing number of "born digital" resources have been added. What these resources share in common is their importance for academic researchers either as primary or secondary sources.

A full range of electronic resources are included in the A-Z list: 
- Acquisition types. Commercial (one-time payment acquisitions and subscriptions), memberships and open access.

- Media types. CD-ROM/DVDs/tapes (stand alone or on a LAN), client/server and online (ftp, streaming audio and video, and Internet).

- Resource types. Indexes, bibliographies and catalogs; abstract and indexing (A\&I) databases; full text or article aggregator databases; book collections; publisher journal collections and selected journals; newspaper collections and news services; reference collections and selected reference works; theses and dissertations collections; numeric data sources; in-house databases; government resources; platforms; portals; selected websites; bibliographic utilities; image galleries, streaming audio and video; and more.

The A-Z list excludes several resource types that appear only in the library catalog and/or in separate A-Z lists: most individual journals, electronic books, data sets and collections, government documents, websites, bibliographic utilities only available to staff, specialized database services, and a growing number of individual electronic reference works.

The study excluded miscellaneous A-Z list entries, including: "see" crossreferences," "superseded by" statements, and print resources.

\section{Data Sources}

Consistent data was available for the full time series; however data for the first four years, 1996-1997 to 1999-2000, was more limited. The primary sources included:

1. The "Databases" A-Z list. Downloads of the A-Z list were captured within a week of the end of each fiscal year, April 30, from 2004-2005 to 2007-2008. Data for earlier 
years were collected from the The Wayback Machine (Internet Archive, 2009), a selection of Internet archive "slices" compiled by the non-profit organization, the Internet Archive. In the latter case, the date nearest to the end of the fiscal year was used. Since this early period does not have other corroborating evidence from local spreadsheets, the electronic resources numbers may be slightly under-counted and therefore results from this period must be interpreted with some caution.

2. In-house Electronic Resource Spreadsheets. The electronic resource librarian (ERL) maintained proto-Electronic Resource Management (ERM) content on Excel spreadsheets from 2000-2001. These spreadsheets tracked all electronic resources over which the ERL has oversight, the majority of which appear in the A-Z list. The spreadsheets tracked titles and collections, and acquisition details.

3. Other Data Sources. The library's acquisitions order records and catalog records were also consulted to verify selected details.

\section{Data Collection Method}

A Microsoft Access relational database was created to track data. SPSS statistical software was used to compile statistics. Electronic resources were counted using various criteria:

- Separately searchable resources, including sub-databases, were counted.

- Resources that came free with the acquisition of another resource were counted.

- Resources available on different platforms were counted as multiple holdings.

- If a resource merged with one or more titles in the course of a fiscal year, it was counted as a separate resource in the year it merged. 
- If a resource split into more than one separately searchable or itemized resource, each part was counted separately in the year the split occurred and thereafter.

- Cancelled resources were counted as holdings in the year they were cancelled.

- A resources migrating to a new vendor was counted only once in the migration year.

- A resource with a name change was counted as one holding in the year of the change.

- Archives were counted only once per resource to avoid skewing the results through the proliferation of multi-year archive acquisitions.

\section{Data Analysis Method}

Net and new electronic resource growth patterns over the time series were analyzed using Microsoft Excel and SPSS. The growth rate was calculated year-over-year on the net and new electronic resources.

\section{Findings}

\section{Data Integrity}

Achieving a high level of data integrity was a challenge. Given the volatility of resources, with name changes, mergers, splits, and ever-changing content, it was necessary from the outset to develop a set of standards for data quantification and recording. What should be counted? How can resources be counted consistently through the time series?

Fortunately, the library used the same principles for inclusion and display in the A to Z list throughout the time series. In addition, detailed in-house spreadsheets covering the last eight years of the time series tracked the same fields consistently. As a result, the data, while subject to the fallibilities of human error and interpretation and the innate 
volatility of the subject matter, has the necessary integrity to give the results and analyses credibility.

\section{“New”vs "Net” Electronic Resources}

Although theoretically possible, in practice the number of new electronic resources acquired in a given fiscal year never equaled the net increase in the number of electronic resources year-over-year. New acquisitions indicate the number of commercial and open access resources ordered and acquired in a fiscal year, while the net increase is the difference between the number of electronic resources listed in the A-Z list year-overyear and reflects such variables as database mergers and splits, cancellations and structural changes to databases. The number of new acquisitions were generally higher than the net increase year-over-year. While the net increase data is important as a measure of overall growth, new acquisitions are a measure of both acquisition range and power, and represent the real scope of new resources encountered by staff and patrons.

\section{Net Electronic Resources Growth Stages}

The study found three distinct net growth stages (see Figure 2 and Table 1) related to three major advances in electronic resource types: bibliographic, full text, and reference. While the numbers may vary within each stage, each stage has a significantly higher mean or average than the previous stage. The average for the second growth stage is 5 times higher than for the initial stage, and the final growth stage is over 2.5 times larger than the second. No notable displacement of electronic resource types occurred over the time series. That is, the majority of bibliographic resources launched in the Bibliographic stage not only continued through to the final Reference stage, but the library also continued to acquire new index and abstract databases in all subsequent stages. 
I. Bibliographic (1996-1997 to 1998-1999). Includes primarily bibliographic abstract and index databases and reflects the library's initial migration of standard bibliographic print resources to online equivalents. Growth is relatively insignificant, at an annual average net increase of 8 resources. The start date of this stage is artificial since earlier data is not available.

II. Full Text (1999-2000 to 2004-2005). After the relatively modest growth experienced in the preceding stage, this long six-year stage coincides with the launch of full text aggregator databases and electronic journal publisher collections, such as Project Muse, BioOne, and ACS Web Editions, in the library's collection. The first electronic book collections were acquired during this stage. The annual average net increase jumps significantly over the previous Bibliographic stage from 8 to 43 .

III. Reference (2005-2006 to 2007-2008). Corresponds with the rise of the reference work (databases and books) in the A-Z list. The annual average net increase jumps more than 2.5 times over the previous stage to 108 (median of 92). The actual duration of this stage can only be speculated on. There is every indication this stage will continue at least until 2008-2009, and perhaps beyond.

\section{Sustained Rapid Growth}

Net electronic resources holdings grew from 51 in 1996-1997 to 646 in 2007-2008 (see

Figure 1), an increase by a factor of 12.7. This growth does not express itself as a classic exponential curve or annual doubling of holdings; nevertheless, it shows a substantial and sustained upward-curving trendline. The arithmetic mean or average annual net increase of electronic resources over the time series was 54 (median of 45) (see Table 1). 
However, the net increase in the final Reference growth stage exceeded both the average and median values by very large margins, nearly doubling or tripling the numbers reported in preceding stages (see Figure 2). Net growth accelerated over time.

[Insert: Figure 1. Net electronic resources holdings at the University of Saskatchewan Library: 1996-1997 to 2007-2008]

[Insert: Figure 2. Annual net electronic resources increase: 1997-1998 to 2007-2008]

\begin{tabular}{lccc}
\hline \multicolumn{4}{c}{ Annual Net Electronic Resources Increase } \\
\hline GROWTH STAGE & FISCAL YEARS & MEAN & MEDIAN \\
I. Bibliographic & $1997-1998$ to 1998-1999 & 8 & 8 \\
II. Full Text & $1999-2000$ to 2004-2005 & 43 & 44 \\
III. Reference & $2005-2006$ to 2007-2008 & 108 & 92 \\
Overall & $1997-1998$ to 2007-2008 & 54 & 45 \\
\hline
\end{tabular}

Table 1. Annual net electronic resources increase: $1997-1998$ to 2007-2008

\section{Net Electronic Resources Growth Rate}

The average annual net growth rate was 27 per cent (median of 22 per cent) over the time series (see Figure 3 and Table 2). An average or above average growth rate was experienced in at the start of each of the last two stages. The growth rate fluctuates over time, rising from a low of 10 per cent at the start of the time series to highs of 68 per cent in the second growth stage and $34 \%$ in the final stage, after which it declines to 16 per cent in the final year of the time series. The low-order smooth polynomial trendline (used to mark trends for fluctuating data), with highest magnitude in the center of the curve, indicates a growth rate curve that generally trends downward at the end of the time series.

The average growth rate of 14 per cent (median of 14 per cent) in the initial stage doubles to 31 per cent (median of 22 per cent) in the second stage (see Table 2). While the number of additional net resources climbs sharply over all three growth stages (see 
Figure 2 and Table 1), growth rates actually declined by $5 \%$ in the transition to the final Reference stage (see Table 2).

[Insert: Figure 3. Annual net electronic resources growth rate: 1997-1998 to 2007-2008]

\begin{tabular}{lccc}
\hline \multicolumn{4}{c}{ Net Electronic Resources Growth Rate } \\
\hline GROWTH STAGE & FISCAL YEARS & MEAN & MEDIAN \\
I. Bibliographic & $1997-1998$ to $1998-1999$ & $14 \%$ & $14 \%$ \\
II. Full Text & $1999-2000$ to $2004-2005$ & $31 \%$ & $22 \%$ \\
III. Reference & $2005-2006$ to $2007-2008$ & $26 \%$ & $28 \%$ \\
Overall & $1997-1998$ to $2007-2008$ & $27 \%$ & $22 \%$ \\
\hline
\end{tabular}

Table 2. Annual net electronic resources growth rate: 1997-1998 to 2007-2008

\section{Net Electronic Resources Doubled in Four Years}

The number of net electronic resources holdings essentially doubled over the last four years of the time series (see Figure 4). There were twice as many electronic resources in the A-Z list in 2007-2008 as there were four years earlier in 2004-2005, and ten times as many as ten years earlier in 1998-1999.

[Insert: Figure 4. Net electronic resources as per cent of 2007-2008 electronic holdings] New Acquisitions Growth: 2000-2001 to 2007-2008

The library acquired on average 76 (median of 60) (see Table 4) licensed or open access electronic resources annually from 2000-2001 to 2007-2008, the eight years where authoritative data is available. The overwhelming majority of the additions were commercial acquisitions. New acquisitions increased from a low of 38 in 2002-2003, to a high of more than 100 in each year of the final stage; a 3 to 4-fold increase (see Figure 5). The polynomial trend line indicates a continuing upward growth curve.

[INSERT: Figure 5. New electronic resources acquisitions: 2000-2001 to 2007-2008] 


\section{New Acquisitions Growth Stages}

The three growth stages observed for net electronic resources can also be applied to new acquisitions (see Table 3). Reliable data is unavailable for the transition from the initial growth stage to the second stage. New acquisitions show a remarkable growth rate with almost a 2.5 -fold increase in the transition from the second to the third and final stage.

\begin{tabular}{|c|c|c|c|}
\hline \multicolumn{4}{|c|}{ New Electronic Resources Acquisitions } \\
\hline GROWTH STAGE & FISCAL YEARS & MEAN & MEDIAN \\
\hline I. Bibliographic & $1997-1998$ to $1998-1999$ & $\mathrm{n} / \mathrm{a}$ & $\mathrm{n} / \mathrm{a}$ \\
\hline II. Full Text & $1999-2000$ to $2004-2005^{*}$ & 49 & 48 \\
\hline III. Reference & $2005-2006$ to $2007-2008$ & 121 & 105 \\
\hline Overall & $1997-1998$ to $2007-2008^{* *}$ & 76 & 60 \\
\hline $\begin{array}{r}\text { *Data available fo } \\
{ }^{\star \star} \text { Data available fo } \\
\end{array}$ & $\begin{array}{l}001 \text { to } 2004-2005 \text { only } \\
2001 \text { to } 2007-2008 \text { only }\end{array}$ & & \\
\hline
\end{tabular}

Table 3. New electronic resources acquisitions: 2000-2001 to 2007-2008

\section{New Acquisitions Growth Rate}

The average annual growth rate for new acquisitions was 19 per cent (median of -3 per cent) (see Figure 6 and Table 4) over the 7 years with meaningful data. The growth rate shows considerable fluctuation with highs of 66 per cent in 2003-2004 and 84 per cent in 2005-2006 and deep lows at three points. The lowest growth rate, -32 per cent, occurs at the end of the time series, in 2007-2008. The polynomial trendline indicates a general growth rate curve that rises to a high in 2004-2005 then trends sharply downward at the end of the time series.

[INSERT: Figure 6. New electronic resources acquisitions annual growth rate: 20012002 to $2007-2008]$

\begin{tabular}{lccc}
\hline \multicolumn{4}{c}{ New Electronic Resources Growth Rate } \\
\hline GROWTH STAGE & FISCAL YEARS & MEAN & MEDIAN \\
I. Bibliographic & $1997-1998$ to $1998-1999$ & n/a & n/a \\
\hline
\end{tabular}




\begin{tabular}{|c|c|c|c|}
\hline II. Full Text & $1999-2000$ to $2004-2005^{*}$ & $8 \%$ & $-7 \%$ \\
\hline III. Reference & $2005-2006$ to $2007-2008$ & $34 \%$ & $51 \%$ \\
\hline Overall & $1997-1998$ to $2007-2008^{* *}$ & $19 \%$ & $-3 \%$ \\
\hline $\begin{array}{l}{ }^{*} \text { Data availab } \\
{ }^{*} \text { Data availab }\end{array}$ & $\begin{array}{l}2001 \text { to } 2004-2005 \text { only } \\
2001 \text { to } 2007-2008 \text { only }\end{array}$ & & \\
\hline
\end{tabular}

Table 4. New electronic resources growth rate: $2000-2001$ to $2007-2008$

Percentage of new electronic resources in net holdings

On average, new acquisitions account for 22 per cent of the net holdings over the time series with available data (see Figure 7). However, new acquisitions fell from accounting for one-third of the A-Z list in 2000-2001 to only one-sixth in 2007-2008. The polynomial trendline illustrates the decline in the final year of the time series.

[INSERT: Figure 7. Ratio of new electronic resources acquisitions to net electronic resources: 2000-2001 to 2007-2008

\section{Discussion}

\section{Electronic Resources Trending $U p$}

Despite indications of growth slowdown towards the end, the annual net increase of electronic resources was significantly higher at the end of the time series than at the beginning by a factor of 12 . Each growth stage (see Table 1) indicates a major leap in average annual net electronic resources, from 8 , to 43 , to 108 , respectively, clearly demonstrating the sustained, rapid pace of net electronic resources growth in a large academic library in recent times.

Five-year Growth Projection to 2012-2013

Projecting forward 5 years to 2012-13, at the average net growth rate of $23 \%$ (calculated on the previous 5 years), there would be approximately 1819 electronic resources listed in 
the databases A-Z list (see Figure 8). This nearly triples the list in five years. Using the much lower average of $16 \%$ from the final year of the time series, the projection drops by almost 500, to 1357 resources, but still doubling the list in five years. Which is the more realistic forecast? The downward trend indicators found in this study favor the lower projection, and recent external fiscal factors may also support a lower projection. These are still very large numbers, with major implications for library systems and services and for reference workers and researchers. It may seem frivolous to make growth projections based on past performance given the unpredictability of events as our current economic woes demonstrate; however there is every indication that the momentum of growth cannot be halted. New kinds of electronic resources continue to emerge, and the demands of our patrons for more electronic content are undiminished.

\section{$100 \pm$ New Acquisitions Annually}

Both new electronic resources acquisitions and the average annual growth rate registered a major jump from the second to the third growth stages (see Tables 3 and 4). On average, 121 new resources were acquired annually in the final, Reference, stage, more than twice as many as in the preceding stage. However, there are indications of a growth slowdown. The downward growth rate and the marked decrease in new acquisitions at the end of the time series appear to signal the start of a negative trend. Together with current economic factors these indicators may forecast a levelling off or contraction of annual acquisitions to approximately $100 \pm$ annually for the immediate future. Still a significant number for a large academic library to manage, but much lower than might have ocurred had growth rate escallation continued.

Average Growth Rate Trending Down 
The exponential upward curve for the net electronic resources growth (see Figure 1) is not duplicated in the net growth rate trendline (see Figure 3). Instead, the growth rate fluctuates widely from year to year and in the final year, falls 18 per cent from the previous very strong year. While 16 per cent growth rate is still relatively high, it is substantially less than the overall average of 27 per cent over the full time series. The polynomial trendline (see Figure 3), indicates a trend downward, but has a low reliability factor $\left(\mathrm{R}^{2}\right)$ for predicting the future $\left(\mathrm{R}^{2}\right.$ is the per cent of variation over the time series (axis X) 'explained' by variation in resources (axis $\mathrm{Y}$ ); the higher the $\mathrm{R}^{2}$, the more likely predictions based on the trendline are strongly supported by the data; an $\mathrm{R}^{2}$ of over 50 per cent indicates high reliability, and less than 20 per cent indicates low reliability). A more reliable indicator is the moving average trendline that echoes the downward trend. While the average net growth rate climbs from 14 per cent to 31 per cent in the transition from the first to the second growth stages, the subsequent transition to the third stage actually indicates a small decline of 5 per cent (see Table 3).

The new acquisitions growth rate (see Figure 6) trendline shows a more reliable indication of a downward trend. It is trending down faster and more deeply than the net holdings growth rate (see Figures 3, 6 and 7). While all these data are not definitive individually, together they support the projection that a small contraction rather than a steep decline for both net holdings and new acquisitions may be in the works in the short term, with new acquisitions contracting somewhat more than net holdings.

\section{Dissecting the Growth Trendline}

Analysis of the annual net growth rate over the time series reveals two remarkable data peaks of 68 per cent and 34 per cent respectively (see Figure 3 ). The moving average 
trendline runs almost parallel. The initial peak for both trend lines coincides with the planning to launch year period (late 1999 to early 2001) for the original CNSLP (now known as CRKN) national consortium suite of electronic resources. The launch heralded a steady rise in library acquisition of full text aggregator databases and publisher electronic journal collections, and coincided with the establishment of a new electronic resources librarian position. Both the CRKN product launch and the new position were consequences of the rising awareness of the importance of electronic resources and start of full text availability. New library acquisitions and national consortia acquisitions models evolved to respond to a growing patron demand for electronic resources. The second, smaller trendline peak coincides with increased availability of electronic books and reference works.

The two growth rate peaks are framed by three low points forming "M-shape" data and moving average trend lines over the time series (see Figure 3). The initial low growth indicators are reflections of the small number of electronic resources available in libraries at the time. Electronic resources were still relatively novel and their potential uncertain. The low point in 2004-2005 coincides with the sabbatical leave of the electronic resources librarian. The low point at the end of the time series may reflect the initial impact of fiscal restrictions as well as the failure of library budgets to grow and adequately support electronic resources acquisition and a growing patron preference. The same "M-shape" data and moving average trend lines are indicated for new acquisitions (see Figure 6). But the low points are deeper and the peaks are higher. The highest acquisition years frame the low year when the electronic resources librarian was on sabbatical leave in 2004-2005 and acquisition decisions were subsequently markedly 
reduced. The higher activity in peak years may partly reflect the anticipation of the absence of the electronic resources librarian and the subsequent operational realities of a catch-up year following the return.

\section{The Impact of Rapid Growth on Reference Workers and Patrons}

Reference workers and patrons were challenged to absorb an annual 22 per cent new acquisitions share of net holdings over the time series on average (see Figure 7). In the initial growth stage, the ratio was as low as 10 per cent or less and change was only 1 per cent year over year. This relatively stable period still had many challenges for reference workers and patrons, particularly in relation to the stability of Internet access, but also the novelty of unmediated searching and the navigation maze from online search results to locating print in the library stacks, but there were no particular challenges in relation to growth. While the introduction and subsequent growth in online full text content availability was welcomed by both staff and patrons, the challenges that this significant mass presented became a challenge in the Full Text growth stage. It took 9 years for the library to reach 50 per cent of the 2007-2008 net holdings level, but only 4 years from 2004-2005 to double in size (see Figure 7).

\section{Conclusion}

\section{Growth is Cumulative}

Despite continuous growth, the electronic resources A-Z list was exceptionally stable over the twelve-years of this study. The majority of resources still in publication from the initial Bibliographic growth stage continued through to the third Reference stage. Few resources were cancelled outright. Changes were primarily due to publisher initiatives: 
mergers, expansions, and ceased publication. Ceased resources were more likely to be open access than commercial. The overwhelming majority of resources persisted through subsequent growth stages, either unchanged or in a merged, split or full text version.

\section{Internal and External Factors Linked to Growth}

Electronic resources growth peaks and lows appear to be aligned with significant internal and external events. The library budget itself can be viewed as a neutral factor since the overall budget remained constant or increased from 0-5 per cent annually over the time series. While the relationship may not be strictly causal, the following selection of factors were strongly associated with growth outcomes.

- Market availability. From the historical period of bibliographic database development until now, there has been a massive increase in available commercial and open access electronic resources. Bibliographic tools and electronic journals are now delivered primarily, and increasingly solely, online. Complete journal backfiles are now consistently available. A similar transformation is underway for book publications. Although starting much later than electronic journals, by 2007-2008 electronic books were a massed presence in the library collection and patrons began to expect to find everything online in the library. Leading publishers are poised to publish their complete monograph frontlists electronically. The range of resource types continues to expand. The digitization of media not traditionally held in library collections or only in special collections has transformed their accessibility, creating a new demand in academic libraries. For example, the presence of streaming audio and video collections and digitized archives is growing. 
- Library consortium membership. Perhaps the single most influential factor behind electronic resources growth, after increased market availability, is library participation in highly effective regional and national acquistions consortia. Consortia extend the value of acquisitions dollars, permitting the library to acquire more electronic resources than is possible institutionally. Savings range from 5 to 80 per cent. A substantial number of the the University of Saskatchewan Library's electronic resources were acquired through consortia: MDLP, SHIRP, COPPUL, and CRKN.

- Print migration to online. The library steadily migrated its print collection to online over the time series. In the initial Bibliographic stage, several standard bibliographic indexes were migrated to available electronic equivalents. First as standalone CDROM, then on LANs, and then online over the Internet. As Internet stability grew and user demand increased, so did the pace of the migration from print to online. The obvious efficiencies of electronic publication drives this trend for publishers and vendors and improved access and functionality drives it for libraries. The winning combination of utility and availability continues to spur the migration to online resources. Faced with the decision to acquire a resource in print or online, liaison librarians default to the online version if funds are available.

- User expectation. Influenced by worldwide market and user trends, the migration from print to online has a momentum of its own. User expectations are a major driving force behind electronic resources growth in academic libraries. At the University of Saskatchewan Library, the launch of a major collection of electronic resources in the spring of 2001 through the national CNSLP was a major trigger for changing user expectations. This modest collection was a relatively massive injection 
of electronic content, creating a critical mass that changed patron expectation for finding online full text, and initiated major changes in how students and researchers conducted their research. Patron expectation of electronic content is central to their approach to the library collection and the library responds by acquiring more electronic resources.

- Functionality development. The progressive development of new electronic resource functionality contributes to their expanded profile and utility. Developments such as basic and advanced search, alerting services, OpenURL linking, and Web 2.0 and social networking functionality have improved usability and contributed to user demand for more resources.

\section{Managing Growth}

Rapid and sustained growth of electronic collections presents challenges for both patrons and library staff. While the ratio of new acquisitions to net holding appears to be decreasing, the actual number of new acquisitions grew annually, with \pm 100 acquired in each of the last three years of the time series. This level of growth creates workload issues for acquisitions, access, and reference work. The library infrastructure is challenged to adopt new resource management systems and practices. Patrons and reference staff are increasingly challenged with how to identify appropriate resources and effectively search this wealth of electronic content. The sheer number of resources increases navigation complexity as do the differences in platforms and functionality. Reference staff mediation can no longer adequately assist users to navigate the range of sources in a timely and targeted way. The number of resources in the A-Z list is now too large and their range too complex for any reference staff member to navigate the list 
comfortably from memory. Libraries have mixed results with managing and providing access to their electronic riches. The library catalog has long ago forfeited its position as the central finding tool for electronic resources. However the long-standing availability of alternate A-Z lists and subject pages are only partial access solutions. As well, the longer the list, the less effective they are as finding aids unless search and faceting functionality are added. ERM systems and search tools such as federated or meta-search systems that permit patrons to simultaneously search multiple resources are next stage electronic resource management solutions that provide better exposure of electronic collections and help to optimize their use.

The persistence of print collection "just in time" collection development policies in the online environment may account for some of the rapid growth reported here. Much electronic acquisition is opportunistic - systematic migration of existing print collections, national consortia initiatives, publisher and consortia offers, and the allure of electronic resource functionality and usability. There are also major space-saving benefits to libraries migrating online. However library budgets have not expanded alongside this vision of an expansive electronic library collection. Higher costs and economic woes are the primary curbs to this desire for universal accessibility. Curbing growth through careful collection development policies can only resolve growth issues in the short term. Failing to support patron information needs is not an option. If a library cannot provide electronic content, patrons will go elsewhere - to open access, to private subscriptions, and ultimately to other academic institutions that can.

\section{Limits to Growth}


While this case study exposes a period of rapid and continuous growth, it cannot be concluded that this pattern will continue into the future. Several factors may modify the trajectory of growth or bring it to a point of stasis or even contraction. While publishers appear to be expanding their electronic resources lists at a great rate and everything of value in print seems to be already or will soon to be digitized, the library's potential for acquiring that richness is reaching foreseeable limits. At least three powerful limits to growth are already having an impact:

- The economic downturn. It is perhaps too early at the time of writing this article, to determine whether the economic downturn that began in 2007 in the United States, and 2008 in Canada, will be long-lived. Some predictions are very dire. In the 20082009 fiscal year, the impact of the downturn is already felt on library endowment funds across Canada and the United States. Library endowment fund income has long been a source for support of specialized electronic resources. As this income dries up and the endowment fund principal itself suffers losses, the ability of a library to support existing resources or to acquire new ones is negatively affected. University endowment funds have not escaped the downturn either. The extent to which there will be a domino effect on library acquisitions budgets is still too early to say. But concerns are growing in the academic community about operating funding as a whole. Library acquisitions budgets suffer in dire economic times. The impact on the Canadian economy of the downturn in early 2009 led to a dramatic fall of the Canadian dollar, and consequently significantly higher costs for electronic resources, and reduced growth potential. If the economic downturn is of long duration, there is a 
risk that instead of growth, academic libraries will experience a contraction of electronic resource collections.

- Finite acquisitions budgets. Even before the economic downturn, library acquisitions budgets were not keeping pace with the rising cost of electronic resources. The average annual increase to cost of renewal is at least $5 \%$. As more and more resources are "born digital" without a cancellable print subscription to cover continuing costs, how will libraries find "new" money for new resources? A budget that merely keeps up with annual inflation is not adequately providing for the funding of new resources. With relatively static or reduced acquisitions budgets, libraries will not be able to sustain even their current collections never mind grow these collections. At some point, the cost of maintenance will exceed the acquisitions budget, and cancellations will ensue. In the future, growth can only be sustained if the university infuses new money into the annual acquisitions budget base or if the income from endowment funds grows. Neither option seems very likely in the current economic climate. When academic libraries in general will hit the acquisitions budget "wall" is not known. But the prospect is looming large. Publishers must soon realize the limits of library budgets and introduce new pricing models that will permit growth and maintain their market share.

- Limits to electronic dominance. Electronic resources now expend the dominant share of the University of Saskatchewan Library's materials acquisition budget. That share is continuing to grow. Protests from patrons to further reductions in print expenditures are already being heard by librarians. The uses and value of print and other nonelectronic media are a continuing factor in an academic library. "Old" media persist in 
libraries long after new media appear to supplant them. Libraries still acquire manuscripts and artifacts, microform, CD-ROMs and DVDs. Print will persist in academic libraries into the distant future. The limit to the electronic resources share of academic library acquisitions budgets is fast approaching.

\section{The Next Growth Stage}

The start of the initial Bibliographic growth stage very likely precedes the start of the time series. More data might only expose an historical launch stage. What and when will the next growth stage be? It is too early to determine the full parameters of the final Reference stage. Does 2007-2008 mark its end or will it continue indefinitely? Will it display ups and downs or a steady trend line downward? Are we on the verge of a significant contraction due to the economic downturn and the limits to growth? While the number of bibliographic, full text, and reference works continues to expand, there are new resource types entering the collection that can only be categorized as "other": digital facsimiles, images, streaming audio and video, interactive modules, and multimedia, with an as yet unknown growth potential that may signal that we are about to enter a new growth stage.

While the acquisition of commercial electronic resources might be slowing down for the moment for reasons described earlier, other avenues for electronic content are proliferating. Non-profit organizations and public institutions are offering open access to their significant out-of-copyright print book collections through mass digitization projects. These projects are not only happening at large well supported libraries like the U.S. Library of Congress, but also at smaller libraries. The digitization of print holdings has the potential to change the face of library collections. The Google Books Library 
Project is another potential game shifter; however, the protracted legal settlement between Google, book publishers and authors is, at the time of writing this paper, still not resolved in the U.S. federal courts and it is therefore premature to speculate on the nature and extent of this project's impact on academic electronic collections.

\section{References}

Aquirre, A. (1976), “The Electronic Library: Bibliographic Data Bases: 1975-76” (book review), Bulletin of the Medical Library Association, Vol. 64 No. 1, pp. 66-67.

Bourne, C.P. (1999), “40 Years of Database Distribution and Use: An Overview and Observation” 1999 Miles Conrad Memorial Lecture, NFAIS Annual Conference, February 23, 1999, Philadelphia, PA, available at: http://www.nfais.org/publications/mc_lecture_1999.htm (accessed 29August 2008).

Bourne, C.P. and Bellardo Hahn, T. (2003), A History of Online Information Services, 1963-1976, The MIT Press, Cambridge, MA.

Bush V. (1945), “As We May Think,” The Atlantic Monthly, Vol. 176 No. 7, pp. 101-108.

The Carnegie Foundation for the Advancement of Teaching (2009), "The Carnegie Classification of Institutions of Higher Education TM", available at: http://www.carnegiefoundation.org/classifications/ (accessed 14 March 2008).

Hawthorne, D. (2008), “History of Electronic Resources”, Yu, H. and Breivold, S. (Eds.), Electronic Resource Management in Libraries: Research and Practice, (Information Science Reference, Hershey, NY, pp. 1-15.

Internet Archive (2009), “The Wayback Machine”, available at: http://www.archive.org/web/web.php (accessed 26 September 2008).

Kyrillidou, M. and Bland, L. (Eds.) (2008), ARL Statistics 2006-2007, Association of Research Libraries, Washington, DC, available at: http://www.arl.org/bm doc/arlstat07.pdf (accessed 13 March 2009).

Krym, N. and VanBuskirk, M. (2001), "Resource-sharing roles and responsibilities for CISTI: change is the constant”, Interlending \& Document Supply, Vol. 29 No. 1, pp. 11-16. 
Lemelson-MIT Program (2002), "Inventor of the Week Archive: Vannevar Bush", available at: http://web.mit.edu/invent/iow/bush.html (accessed 29 August 2008).

Lerner, F. (1999), Libraries Through the Ages, The Continuum Publishing Company, New York, NY.

Neufeld, M.L. and Cornog, M. (1986), “Database History: From Dinosaurs to Compact Discs,” Journal of the American Society for Information Science, Vol. 37 No. 4, pp. 183-190.

Wedgeworth, R. (Ed.) (1993), World Encyclopedia of Library and Information Services, American Library Association, Chicago, IL.

Williams, M.E. (1985), “Electronic Databases”, Science, Vol. 228 No. 4698, pp. 445-450. 